\title{
A GENERALIZED CAUCHY-SCHWARZ INEQUALITY
}

\author{
MOWAFFAQ HAJJA
}

Abstract. In the course of realizing certain triangle centers as points that minimize certain quantities, C. Kimberling and P. Moses, in Math. Mag. 85 (2012) 221-227, discovered an inequality in three variables that generalizes the Cauchy-Schwarz inequality, and made a conjecture regarding a generalization of that inequality to an arbitrary number of variables. In this paper, we give a proof of a stronger form of that conjecture.

\section{Mathematics subject classification (2010): 51M16, $51 \mathrm{M} 04$.}

Keywords and phrases: Cauchy-Schwarz inequality, constrained critial point, extrema, Hessian, Lagrange's multipliers, Lemoine point, positive-definite matrix, quadratic form, symmedian point, triangle centers.

\section{REFERENCES}

[1] M. HaJja, Radical and rational means of degree two, Math. Inequal. Appl. 6 (2003), 581-593.

[2] M. HAJJA, Review of [8], Zentralblatt Math. Zbl 1260.51005, 2014.

[3] M. HAJJA, M. HAYAJNEH, Impurity of the corner angles in certain special families of simplices, J. Geom. 105 (2014), 539-560.

[4] H. HANCOCK, Theory of Maxima and Minima, Dover, N. Y., 1993.

[5] C. Hassell and E. ReEs, The index of a constrained critical point, Amer. Math. Monthly 100 (1993), 772-778.

[6] R. A. Horn, C. R. Johnson, Matrix Analysis, Cambridge University Press, Cambridge, 1994.

[7] C. Kimberling, Triangle centers and central triangles, Congr. Numer. 129, (1998), 1-285.

[8] C. Kimberling, P. Moses, Inequalities involving six numbers, with applications to triangle geometry, Math. Mag. 85, (2012), 221-227.

[9] C. Kimberling, Encyclopedia of Triangle Centers, http://www.ETC.

[10] J. A. Sсотт, On the Lagrange method for constrained critical points, Math. Gaz. 91 (2009), 81-85.

[11] P. ShutLer, Constrained critical points, Amer. Math. Monthly 102 (1995), 49-52. 